\title{
El legado de la política hidráulica de Epitácio Pessoa: llevando el agua a su molino ${ }^{1}$
}

Tim Neufert

DOI - 10.25160/v5i2.d8

\section{Introducción}

Mientras que la literatura académica sobre la historia de la sequía en el Nordeste brasileño es muy extensa, los estudios críticos sobre una de sus figuras principales, Epitácio Pessoa, son relativamente escasos, tomando en consideración su importancia durante la Primera República. Incluso autores que señalan detalladamente el abuso dentro de la política de la sequía y del poder en esta época, eluden incluir a Epitácio Pessoa inequívocamente en sus críticas como si se tratara de salvaguardar la imagen del gran nordestino. A menudo se reproducen los elogios del propio entorno de Pessoa o los argumentos que este mismo usaba para defender su política hidráulica. Por ejemplo, en un reportaje especial premiado del año 2010 se comparan los logros para el Nordeste de Pessoa con los de Lula da Silva, sin cuestionar ni los de uno ni los de otro.

En el presente artículo, primero se retratarán algunas de las opiniones emblemáticas sobre Epitácio Pessoa que construyen su imagen y se reflejan en su recepción historiográfica. Después, éstas se contrastarán con su actuación política, enfocando la orientación económica de las medidas contra los efectos de la sequía en contraposición a la falta de reformas progresistas. En un tercer paso se retomará la comparación entre Epitácio Pessoa y Lula da Silva con respecto a la política hidráulica actual, sin limitarla a la persona de Lula da Silva, ya que se trata de la política general de su partido, el Partido de los Trabajadores, que fue compartida y continuada por su sucesora Dilma Rousseff. Entre promesas, perspectivas y alternativas, nos preguntaremos donde terminará el agua del Nordeste.

\section{La imagen de Epitácio Pessoa y su recepción historiográfica}

\section{Comparación con Lula da Silva y veneración como "redentor del Nordeste"}

\footnotetext{
${ }^{1}$ El artículo se basa, en gran parte, en mi tesis doctoral: Die Macht der Dürre. Wasser und Politik in Brasilien in der Zeit von Epitácio Pessoa (1877-1930), Köln: Böhlau Verlag, 2015 ("El poder de la sequía. Agua y política en Brasil en los tiempos de Epitácio Pessoa"). Las fuentes usadas en el libro se pueden descargar en: www.boehlau-verlag.com/9783-412-50144-0 (Downloads/Bonusmaterial).
} 
En un reportaje especial premiado del Diário de Pernambuco de 2010 se establece un paralelismo entre dos presidentes de origen nordestino, el pernambucano Luiz Inácio Lula da Silva (2003-10) y el paraibano Epitácio Lindolfo da Silva Pessoa (1919-22). Se destaca la 'solución hidráulica' del gobierno Epitácio Pessoa que destinó a la llamada "lucha contra los efectos de la sequía" el 15\% del presupuesto fiscal - la participación más alta hasta hoy. Según el reportaje, las obras emprendidas por Epitácio Pessoa sólo se pueden comparar con las del gobierno Lula da Silva (Santiago, 2010).

Epitácio Pessoa (1865-1942), el único presidente oriundo del Nordeste en la Primera República (1889-1930), es celebrado como 'salvador' de su región natal castigada por la sequía. La expresión "redentor do Nordeste" fue utilizada por su hija y biógrafa Laurita Pessoa Raja Gabaglia. Ella elogió los esfuerzos de su padre como "obra social de uma audácia que ainda não tivera precedentes no Brasil" (Gabaglia, 1966: 79). Su hermana Helena Sayão Pessoa realzó la "solidariedade humana" de Epitácio Pessoa, particularmente "para com os pobres, os humildes, e os injustiçados da sorte" (Pessoa, H., 1966: 136).

\section{Opinión de historiadores: la única excepción positiva de la corrupta Primera República}

Con el mismo entusiasmo, el historiador Marco Antonio Villa habla de una "grande ousadia” (Villa, 2001: 129), resaltando la política hidráulica de Epitácio Pessoa como única excepción positiva en la, por lo demás corrupta, Primera República. Aprecia sobre todo el planteamiento integral que incluía presas, pozos y sistemas de irrigación y que abordaba la construcción simultánea de vías de transporte y comercio para el fomento del desarrollo económico de la región (id., 2005: 16-17). El historiador José Batista Neto también critica rotundamente el régimen político de la 'era de las oligarquías' $\mathrm{y}$, por otra parte, corrobora la imagen muy distinta de Epitácio Pessoa, la de un empeño esperanzador para el Nordeste:

O interesse com os problemas do Nordeste, no governo Epitácio, não é meramente discursivo. É organizado e implementado o maior plano de obras e destinado um portentoso volume de verbas para execução desse plano na região semi-árida. Nunca antes se assistira a um Governo tão efetivamente preocupado com as questões da região semi-árida, sobre ela 
refletindo-se e praticando-se uma política coordenada, sistemática e permanente. (Batista, 1986: 109)

(...) o governo Epitácio representa a operacionalização, pela primeira vez, de uma ação articulada - estudos científicos e obras - de forma efetiva no sentido de dar soluções visíveis, palpáveis e concretas para o problema da seca. Mostram-se, pela ação, os caminhos da viabilidade econômica da região, mesmo com todas as dificuldades. (Ib.: 166-167)

Se da la impresión de que los proyectos de Epitácio Pessoa habrían alcanzado a "todas as classes indistintamente" (ib.: 168) ${ }^{2}$ si no hubiera sido por la repentina y casi completa anulación de estas medidas bajo el mandato del siguiente presidente Artur Bernardes:

(...) findos os três anos de agitação [das obras contra as secas do governo Epitácio Pessoa], quase febris, suspensas as obras em 1923 pelo presidente Bernardes, os trabalhadores ficaram desempregados e sem a mínima perspectiva de dias melhores. (Gurjão, 1994: 49)

\section{Partidarios contemporáneos de Epitácio Pessoa: “el Nordeste será el granero de Brasil”}

Toscano Espinola, antiguo secretario de Epitácio Pessoa, dijo al respecto de las obras prematuramente interrumpidas: "se todo o plano de Epitácio tivesse sido cumprido, hoje não estariamos a pensar em alimentação. O Nordeste seria o celeiro do Brasil." (Espinola, 6/7/1952) $)^{3}$ La prensa gubernamental de Paraíba incluso preveía que "certamente o problema das sêccas será resolvido durante a vigencia administrativa do eminente (...) presidente da Republica" ("Os serviços das obras contra as sêccas na Parahyba". 22/2/1920: $1)$.

Hoy sabemos que Epitácio Pessoa no acabó con el problema de la sequía, ni es probable que lo hubiera hecho, de concluir las obras planificadas. Habría acabado, al mismo tiempo, con la política de la sequía, secando una fuente que proporcionaba liquidez e influencia política a la clase dominante regional que de otra manera difícilmente habría conseguido mantenerse en el poder. Puestos políticos dentro del aparato administrativo de la 'lucha contra la sequía' salvaron a una élite económica y políticamente decadente. Las obras públicas dotaron a los potentados locales de comisiones lucrativas y a los

\footnotetext{
${ }^{2}$ El propio Batista relativiza el alcance de las medidas de Epitácio Pessoa (ver abajo e ib.: 167: "Finalmente, a ação epitacista não considera a questão fundiária, nó da problemática regional.”).

${ }^{3}$ Todas las citaciones mantienen la ortografía original.
} 
terratenientes allegados de carreteras de acceso y líneas ferroviarias para potenciar el comercio de sus productos y de pozos y embalses, la mayoría de veces en tierras privadas, para sostener su actividad agropecuaria. En nombre de la ayuda a las masas pobres, las masas de agua acumuladas beneficiaron principalmente a una minoría privilegiada:

(...) a ação epitacista é tremendamente restritiva. Ela parte de uma visão reducionista dos problemas da região, típica da classe social que representa - proprietários rurais do semi-árido. (...) A propriedade e a questão fundiária ficam intocadas. (Batista, 1986: 167-168)

\section{El movimiento reformista: críticos contemporáneos de Epitácio Pessoa}

Al contrario que algunos investigadores que llevan más de 20 años desenmascarando el discurso de la sequía (entre ellos Rosa Maria Godoy Silveira, Durval Muniz de Albuquerque Júnior, Frederico de Castro Neves e Iná Elias de Castro)4, muchos historiadores - aún en publicaciones recientes - coinciden en aspectos centrales con la versión pulida en los tiempos de la Primera República: el punto de mira es la calamidad natural (y no la responsabilidad humana), se exalta la proeza de nordestinos singulares como Epitácio Pessoa y se denuncia el obstruccionismo por parte de los políticos del Sur brasileño. $^{5}$

La oposición contra la política de la sequía de Epitácio Pessoa existía sin duda pero no se la puede limitar a la simple fórmula del antagonismo tradicional entre Norte y Sur. Examinando las biografías de algunos de los críticos más notables, nos encontramos con el trasfondo sociopolítico de los primeros movimientos reformistas de la segunda década del siglo XX. A este grupo de precursores de una legislación laboral y social progresista pertenecían parlamentarios como Maurício de Lacerda y Nicanor Nascimento que censuraban duramente la actuación de Epitácio Pessoa. ${ }^{6}$ Ellos defendían la protección de los trabajadores, fuera en las grandes urbes del Sur, fuera en el distante polígono de la sequía en el Nordeste, donde la financiación pública no parecía llegar a los proyectos

${ }^{4}$ Cf. Silveira, 1984; Albuquerque Jr., 1988; id., 1999; Neves, 1994; id., 1995; Castro, 1992; id., 1996 y también Oliveira, 1981; Haesbaert, 1997; Gomes, A., 1998.

${ }^{5}$ Como ejemplo de esta postura véase Villa, 2001: 102-106, 110, 114, 125-130.

${ }^{6}$ Sobre la defensa parlamentaria de los derechos laborales véanse Lacerda, 13/7/1917, 14/7/1917, 18/7/1917: 908-909, 956-958, 989-993 y Nascimento, 14/7/1917: 956-958; sobre las circunstancias sociales véanse Borges, 1992: 145; CPDOC/ FGV, A era Vargas y además Mendes, 2009: 37-38, 46-49; sobre la crítica contra Epitácio Pessoa véase Nascimento, 9/7/1920: 158 y concretamente sobre la política de la sequía Lacerda, 13/7/1920: 449. 
hídricos sino a los bolsillos híbridos de los comisionados de las obras. Este contexto ideológico se ha ignorado completamente en la historiografía de la sequía. En vez de analizar el origen sociopolítico de estos críticos y así sopesar su credibilidad, se ha adoptado ampliamente el argumento del propio Epitácio Pessoa de que se trataba de una mera campaña difamatoria contra el Nordeste a favor de los intereses políticos del Sur.7

En cuanto al movimiento obrero, Pessoa reaccionó al supuesto 'peligro anarquista' con todo el rigor de la ley, deportando a los 'elementos subversivos' (CPDOC/ FGV, A era Vargas; Borges, 1992: 145). A la crítica de los opositores en el congreso respondía con sarcasmo:

Agora, as acusações variam de rumo. Já não se trata da utilidade das obras ou dos processos de sua execução, mas do impudor com que o govêrno, por espirito de regionalismo e de familia, tem malbaratado perto de 200.000:000\$ nas mais escandalosas deshonestidades para proveito proprio, de conterraneos e parentes, sem que nada haja feito ainda no Nordéste, a não ser importar algum material para logo abandonal-o ás intemperies na beira das estradas. (Pessoa, E., 1/6/1922: 1)

\section{Paradoja historiográfica: la distinción entre la oligarquía y el oligarca Epitácio Pessoa}

Epitácio Pessoa era un orador muy hábil y elocuente y se defendía extensamente en sus discursos y escritos, ${ }^{8}$ pero la corrupción dentro del ámbito de las obras contra la sequía estaba tan generalizada desde sus inicios que no se podía desmentir. Por consiguiente, se la calificaba de mal inevitable que se restringiría a niveles negligibles y que, respecto al período gubernamental de Epitácio Pessoa, no tendría nada que ver con el presidente. ${ }^{9}$ Siguiendo esta lógica, el historiador Marco Antonio Villa ironiza sobre las críticas contra Epitácio Pessoa y, haciendo uso de un juego de palabras, banaliza la corrupción sistemática - la llamada 'industria de la sequía' - en el Nordeste:

\footnotetext{
${ }^{7}$ El historiador José Batista Neto lo expresa de esta manera: "As críticas têm autoria certa: parlamentares e jornalistas identificados com os interesses políticos do Sudeste.” Batista, 1986: 147.

${ }^{8}$ Ante las críticas contra su gobierno, Epitácio Pessoa reaccionó con un escrito apologético de 600 páginas: Pela Verdade, $1957\left(1925^{1}\right)$.

${ }^{9}$ Acerca de la corrupción en el ámbito de la ayuda a las víctimas de la sequía desde 1877 véanse: Rodrigues, 11/2/1879: 465; Borges, 13/7/1920: 447; id., 21/12/1920: 340. Acerca de la presidencia de Epitácio Pessoa: Barbosa, 19/4/1922: 1.
} 
Acabou sendo criada uma 'indústria da denúncia' [do Sul], como se qualquer ação do poder público federal no Nordeste representasse um desvio de recursos para favorecer as oligarquias. (Villa, 2001: 252) ${ }^{10}$

Otros investigadores como Eliete Gurjão y Lúcia Ferreira describen exhaustivamente la 'industria de la sequía', incluyendo el clientelismo y nepotismo oligárquicos en Paraíba, pero también rehuyen dirigir esta crítica directamente al líder oligárquico más influyente y exitoso de esta provincia - Epitácio Pessoa (cf. Gurjão, 1994: 30-32, 58-60). Ferreira más bien engloba a Pessoa en la categoría de los que estaban amargamente decepcionados porque "acreditavam nos planos e projetos, sem avaliar a força dos interesses oligárquicos" (Ferreira, 1993: 127)11. En este sentido, ella trata a la oligarquía y a su líder como dos entes independientes, aun hasta con intenciones opuestas. Así mismo, al hablar de la malograda construcción de un puerto fluvial en la capital paraibana, Lúcia Ferreira parece eximir al presidente Pessoa de una posible implicación, aportando una citación del historiador Apolonio Nóbrega:

Infelizmente, gastaram mais de vinte mil contos e deixaram em situação pior do que antes dos trabalhos. Apenas umas estacas ficaram sepultadas nas margens do Sanhauá, denunciando o esforço de um homem e a desonestidade de uma época. (Nóbrega, 1950: 153, citado por: Ferreira, 1993: 105)

Una conversación entre Epitácio Pessoa y su compatriota paraibano César de Oliveira Lima, recordada y transmitida por éste, refuerza la versión de que Pessoa sufrió un gran engaño y posterior desengaño:

Ali foram gastos 27 mil contos sem nenhum resultado. Nunca fui tão mal informado. (...) Jamais irei à minha terra, depois de sofrer tamanha humilhação (...). ${ }^{12}$

\footnotetext{
${ }^{10}$ No quiere decir que el autor no haya hecho ninguna crítica de la 'industria de la sequía' (cf. ib.: 248, 251-252) sólo que en comparación con su narrativa principal ocupa una posición marginal en su libro sobre la sequía. Para un análisis detallado de la valoración de Pessoa por parte de los historiadores Lúcia Ferreira, Eliete Gurjão, José Batista Neto y Marco Antonio Villa, sus interpretaciones críticas inclusive, véase Neufert, 2015: 342-364.

${ }^{11}$ En este contexto y ampliando la perspectiva a la esfera nacional, Ferreira menciona a Epitácio Pessoa de la siguiente forma: „Não seria um presidente, isoladamente e sem bases políticas nacionais sólidas, que mudaria os rumos da ação, a qual exigia a continuidade de projetos por vários governos.“ Id., 1993: 126.

${ }^{12}$ Pessoa, E., conversación con César de Oliveira Lima (Rio de Janeiro, 1937), atestiguada por el sobrino Antonio Pessoa, registrada por el escritor Alfio Ponzi, publicada por José Joffily y citada por Melo, 2005: 139.
} 
Mientras que estos testimonios representan a un Epitácio Pessoa ajeno a lo que fue el mayor escándalo de las obras contra la sequía durante su mandato, el relatado papel de desinformado es completamente ajeno a su carácter y estilo político en general. La correspondencia privada de Epitácio Pessoa con familiares y partidarios en Paraíba demuestra el estrecho vínculo entre la oligarquía y su jefe político, quien movía todos los hilos desde Rio de Janeiro y continuamente se informaba de los sucesos relevantes en su provincia natal. ${ }^{13}$ Por lo tanto, es muy improbable, y en cierta medida impensable, que el meticuloso Epitácio Pessoa no estuviera al corriente de los pormenores esenciales de esta obra. En primer lugar, porque era la más onerosa - y supuestamente honorable - de su gestión, y además, porque desde el inicio el elevado nivel de riesgo era conocido. La evaluación pericial descartaba unánimemente la operación por la deficiencia del lugar y la inviabilidad técnica de las construcciones. Los ingenieros recomendaban el uso del puerto marítimo en Cabedelo, a 18 kilómetros de distancia. Pasando por encima de las objeciones, la decisión de Epitácio Pessoa a favor del costoso e impracticable puerto fluvial se debía a motivos políticos, con ganancias inminentes por parte de los empresarios locales, vinculados al presidente. ${ }^{14}$ En consecuencia, el escándalo del puerto no se traduce apenas en el fraude de los realizadores y el correspondiente fracaso técnico evidente, con los cimientos hundidos a la vista de los transeúntes estupefactos. La responsabilidad se remonta a la controvertida apuesta de Epitácio Pessoa por los intereses particulares de sus partidarios, en contra de los intereses públicos.

\section{Orientación económica de la política de la sequía de Epitácio Pessoa Apoyo al comercio}

Una vez abandonado el experimento fallido del puerto fluvial, Epitácio Pessoa pujó por sacar adelante la construcción de una carretera comercial de la capital paraibana al puerto de Cabedelo. Según telegramas entre Epitácio Pessoa y su sobrino João Pessoa, en este momento gobernador de Paraíba, el entonces senador Epitácio Pessoa quería aprovechar para tal propósito 400 contos de un total de 2400 contos de ayuda para los afectados de la sequía (Pessoa, E., 9/11/1928). En cambio, João Pessoa se negaba a utilizar este dinero en la

\footnotetext{
${ }^{13}$ Véanse, entre otros, Pessoa, E., 22/4/1915; id., 5/5/1917; id., 18/2/1928: 4; id., 31/8/1928: 1-2; id., 11/9/1928; id., 30/10/1928; Suassuna, 4/2/1928: 3; Pessoa, João, 2/11/1928.

${ }^{14}$ Joffily, José. 1983. Porto político. Rio de Janeiro: Civilização Brasileira, p. 24, 35-36, citado por: Gurjão, 1994: 5960; Pessoa, E., 3/5/1922: 555; Trigueiro, 1982: 69. Sólo después de 1930, cuando la era Pessoa ya había llegado a su fin, se construyó el nuevo puerto, esta vez en Cabedelo y con gastos mucho más moderados (ib.).
} 
zona costera, lejos del núcleo de la sequía del cual escribió en su respuesta telegráfica: “grande população faminta pt. (...) Precisamos soccorrer urgencia população desta zona pt. Não convém pois retirar daquella somma 400 contos estrada Cabedello littoral onde não ha fome pt. (...) Trata-se caso calamidade pt." (Pessoa, J., 10/11/1928) A lo que respondió Epitácio Pessoa: "tratarei obter alguma cousa aparte para estrada Cabedello tenho enviado mensagem congresso" (Pessoa, E., 15/11/1928). Es decir, a pesar de la descripción de penuria en el interior, Epitácio Pessoa seguía centrándose en la carretera al puerto marítimo, que era importante para los productos de exportación.

\section{Subsidios para los estados}

Aunque la política hidráulica de Epitácio Pessoa principalmente era de cuño económicopolítico, ${ }^{15}$ en su discurso público el presidente nordestino insistía en que los usufructuarios serían los más necesitados en el sertão. En su primer mensaje al congreso del 3/9/1919, Pessoa denominó las obras contra la sequía como "uma dívida de honra para com a população pobre do interior, a quem quase tudo tem faltado" (Pessoa, E., 1957 (19251): 266). Lo que Pessoa no quería era que la ayuda llegase directamente a las manos de los indigentes. Durante más de veinte años, el parlamentario y posteriormente senador Epitácio Pessoa se esforzaba por que los "socorros aos indivíduos flagelados" se convirtieran en "socorros aos Estados flagelados", que las 'limosnas desmoralizadoras' se convirtieran en 'obras utilitarias' (Pessoa, E., 29/11/1915: 383; cf. también id., 30/11/1915: 387), sobre las que los representantes políticos - o sea la oligarquía - podían decidir a su antojo.

El concepto de ayuda paternalista, que impide cualquier desarrollo de autonomía de la población y demuestra una gran desconfianza - si no un gran desprecio - respecto a sus virtudes, ya fue delineado por Pessoa en su primer año en el congreso:

A distribuição de generos alimenticios feita gratuitamente, feita como uma esmola áquellas populações tem, antes de tudo, o grande inconveniente de despovoar as zonas de cultura, attrahindo os indigentes para os centros populosos, conservando-os na ociosidade e no vicio, (...) porque esta gente perdendo os habitos do trabalho e encontrando sustento facil e commodo, não voltam ao campo ainda mesmo depois que o inverno vem renascer a esperança de uma nova época de abundancia e de fartura. Parece-me que

\footnotetext{
${ }^{15}$ Cf., por ejemplo, Pessoa, E., 3/5/1921: 232. Esta conclusión también se ha señalado en Lewin, 1987: 110.
} 
o auxilio do poder federal deve ser dado em troca de serviços de utilidade publica, prestados em vias ferreas, em linhas telegraphicas, em açudes, em construcções de qualquer natureza, que por um lado proporcionando aos indigentes occupação decente nas proprias regiões em que habitam, por outro lado contribuam para o engrandecimento da riqueza nacional ou do Estado. (Pessoa, E., 20/8/1891: 334-335)

\section{Omisión de reformas progresistas}

Epitácio Pessoa ni realizó reformas agrarias orientadas hacia las necesidades de los pequeños agricultores ni llevó a cabo los sistemas de irrigación que expresamente había prometido a "essa gente laboriosa" en la zona de la sequía (Pessoa, E., 3/5/1920: 183). Desde el punto de vista emancipatorio, la intervención estatal en el Nordeste fue contraproducente ya que perpetuó la dependencia socioeconómica de la población campesina, fomentando la concentración de la tierra y el monopolio de los recursos hídricos en manos de los coronéis (Albuquerque, 1988: 387, 389; Gurjão, 1994: 31, 87). En defensa de Epitácio Pessoa se podría argumentar que actuaba según el espíritu de su tiempo que era el paternalismo de la era oligárquica. Por otra parte, varios políticos contemporáneos e incluso anteriores, sí reivindicaban reformas progresistas en los sectores de la educación, los derechos laborales, la propiedad agraria y el uso de las reservas de agua.

En el congreso algunos parlamentarios manifestaban la urgencia de invertir en la formación escolar básica de los estratos sociales más bajos:

(...) o problema (...) da instrucção (...) é o de construir de cima para baixo. Cuidamos da instrucção superior e de formar doutores em direito, em medicina, em engenharia, em arte militar, esquecendo a instrucção primaria e profissional, construindo, desse modo, uma Nação de 90\% de analphabetos dirigida por uma classe limitadissima de homens sem uma intuição segura da vida pratica. (Lamartine, 23/11/1915: 384)

Los arriba mencionados militantes del movimiento obrero exigían la regularización del trabajo nocturno de mujeres y niños, la jornada de ocho horas e indemnizaciones en casos de accidentes laborales: 
(...) quanto aos contractos de trabalho (...) [e] aos seus derivados, nos salarios, nos accidentes, na assistencia a menores, a mulheres, a aprendizes, (...) [a] reivindicação (...) dos syndicatos operarios (...) [é]: ‘1’ , o respeito ao direito da greve $(. ..) ; 2^{\circ},(.$.$) o direito de associação para os$ trabalhadores; (...) $4^{\circ}$, que seja abolida, de facto, a exploração do trabalho dos menores de 14 annos nas fabricas (...). (...) $5^{\circ}$, que os trabalhadores com menos de 18 annos não sejam occupados em trabalhos nocturnos. (...) 6. Que seja abolido o trabalho nocturno da mulher.' (Lacerda, 18/7/1917: 990-992)

Ingenieros y agrónomos demandaban proporcionar tierra e irrigación a los pequeños campesinos para hacerlos menos dependientes del clima y de los terratenientes:

Seria conveniente que, de algum modo, se reservasse alguma boa porção de terra para arrendar-se à pobreza por preços cômodos, de sorte que pudessem todos ter meios de trabalho; o que não sucederia se ficassem essas terras em poder de particulares, que sem dúvida mais cuidariam de seus interesses próprios do que dos da pobreza. (Retumba, 1912: 211-212, citado por Ferreira, 1993: 57)

Um governo serio não póde, com o dinheiro arrancado ao povo, sob a fórma de impostos pesadissimos beneficiar propriedades alheias; é (...) uma sinecura, debaixo da formula de emprego publico, e a exploração sob qualquer fórma, do Thesouro Nacional (...). Atravessar estas terras aridas, sem agua, sem valor, por um canal de irrigação, de um custo elevadissimo, sem desapropriar os terrenos na faxa sujeita ás irrigações directas e á administração do canal, além de uma falta de bom senso e um incitamento á especulação, seria comprometter o resultado financeiro do canal, cujas aguas atravessariam então leguas e leguas de terrenos incultos, cujos pseudos-proprietarios apenas aguardariam a alta e a procura, para impôr preços fantasticos. O interesse do Thesouro Nacional, a garantia do capital empregado, o desenvolvimento rapido do paiz, o proprio bom senso, exigem que os terrenos directamente irrigados e situados numa certa distancia de ambos os lados do canal sejam propriedade do mesmo, sujeitos á sua administração, ou cultivados 
directamente, ou arrendados ha longo prazo mediante contracto. (Bouchardt, 23/5/1915: 1)

Toda a questão cifrar-se-á em não construir canaes em terrenos alheios para ficarem improductivos, ou em todo o caso enriquecer alguns á custa do erario publico (...). (Id., 25/5/1915: 1)

Así pues, estas tendencias también formaban parte del espíritu de la época, un espíritu vanguardista al que no se sumó Epitácio Pessoa.

\section{Conclusiones y comparaciones: promesas, perspectivas y alternativas \\ El "nuevo Nordeste" - ¿granero de Brasil u oasis de exportación?}

¿Cuál es la situación hoy? ¿Cuál es el legado de la política hidráulica de Epitácio Pessoa? Desde la democratización las condiciones políticas y sociales han mejorado considerablemente, llevando a una importante reducción de la indigencia. Durante el mandato de Luiz Inácio Lula da Silva, según datos de la Organización de las Naciones Unidas para la Alimentación y la Agricultura (FAO), la pobreza total del país bajó del 36,4\% en 2003 al 20,9\% en 2011, en la zona rural del 53,2\% al 36,1\%. ${ }^{16}$ Referente al desarrollo económico en la zona de la sequía se habla de los "novos Sertões" (Gomes, G., 2001: 8-9, 24-25, 194, 197-210, 229-234). No obstante, muchos observadores dudan que este 'novo nordeste' llegue a ser el granero de Brasil augurado por los correligionarios de Epitácio Pessoa. Más bien temen que forme parte de otra etapa de la larga historia de exportación de materias primas favoreciendo predominantemente a un pequeño grupo de industriales agrarios.

En cuanto a la política hidráulica, el trasvase de aguas del río São Francisco, esbozado por primera vez a mediados del siglo XIX y descartado varias veces por los gastos extremamente elevados y la inviabilidad técnica (Aguiar, 1983: 50-51; Araripe, 27/6/1877: 281; Ferreira, 1993: 53, 60), se convirtió en una prioridad de los gobiernos de Lula da Silva y de su sucesora del Partido de los Trabajadores, Dilma Rousseff. Aún no se puede evaluar los resultados del proyecto, ya que su conclusión se ha aplazado reiteradamente y ahora después de significativos aumentos de presupuesto - está prevista para el año 2017, por lo menos respecto a los canales principales. ${ }^{17}$ Lo cierto es que las obras despertaron una gran

\footnotetext{
${ }^{16} \mathrm{CEPAL} / \mathrm{FAO} / \mathrm{IICA}, 2013: 216$. La pobreza extrema total del país se redujo del 10,6\% en 2003 al $6,1 \%$ en 2011 , en la zona rural del $22,1 \%$ al $14,9 \%$ (ib.).

${ }^{17}$ El presupuesto de costes subió de 1,5 mil millones Reais (1998, aún del gobierno de Fernando Henrique Cardoso) a R \$ 4,8 mil millones (2005), después a R \$ 8,2 mil millones (2015), y la última estimación es que la construcción de los
} 
polémica incluso antes de su comienzo en el año 2007. Los defensores de la transposição, por ejemplo el catedrático de economía Carlos Lessa (UFRJ), resaltaron el necesario abastecimiento de las crecientes ciudades, las nuevas industrias y la agricultura (Lessa, 20/6/2005 y 6/7/2005). Según la planificación inicial del gobierno, el 71\% del agua se emplearía para la agricultura irrigada, el 25\% para los centros urbanos y el $4 \%$ para los asentamientos rurales (Furtado, 2/2/2005b: 9). ${ }^{18}$ Siendo el suministro de las ciudades una necesidad incuestionable, ${ }^{19}$ sí surgieron dudas acerca de quién disfrutaría del agua para la agricultura irrigada. Oficialmente se habla de "amenizar o sofrimento das populações mais castigadas", de "gerar renda e desenvolvimento socioeconômico das famílias" y de que ya en la primera fase el $40 \%$ de la población del sertão se beneficiaría (Ministério da Integração Nacional, 2016; "Do rio para o sertão", 2005: 23). Sin embargo, la experiencia con proyectos anteriores ha demostrado que muchas veces normativas bien intencionadas no son duraderas o son evadidas por empresas exportadoras de alta capacidad financiera que compran las tierras irrigables y así sacan provecho de las inversiones públicas (Ramos, 8/4/2012). ${ }^{20}$ Por eso, los detractores de la transposição recelan de que - exceptuando el imprescindible y urgente aprovisionamiento de las ciudades - los recursos hídricos serán utilizados principalmente por las grandes explotaciones agropecuarias de frutas, verduras y camarones destinados a la exportación ("Do rio para o sertão", 2005: 23; Ab'Saber, 22/3/2011; id., 2006: 13). Ante estas perspectivas, ponen en tela de juicio la justificación socioeconómica del megaproyecto del São Francisco, cuyos objetivos fueron clasificados por el Banco Mundial como tecnológica y comercialmente ambiciosos, pero carentes de un gran alcance social. Debido a la alta concentración de tierras, primero habría que aclarar y modificar la situación de la propiedad agraria en las zonas atendidas. Además, el Banco Mundial señaló que las consecuencias para la naturaleza no se habían estudiado debidamente y recomendó, como alternativa, la construcción de pequeños y medianos

canales principales superará los R\$ 9 mil millones (Gomes, G., 2001: 52; "Do rio para o sertão", 2005: 22; Fernandes, 23/3/2012; Ministério da Integração Nacional, 16/3/2012 y 23/2/2015; Cruz/ Amora, 12/7/2016).

${ }^{18}$ En la presentación actual del proyecto, bajo el título "Uso previsto para a água", ya no se especifican porcentajes (Ministério da Integração Nacional, 2016).

${ }^{19}$ En este momento (dic. 2016), el agotamiento del agua es una amenaza real en ciudades como Campina Grande/ Paraíba, de unos 400.000 habitantes, donde ya se está aplicando el racionamiento de agua, cortándolo en los hogares durante la mitad de la semana. El único recurso factible a corto plazo, aunque poco conveniente ni convincente (menos aún para capitales estatales como Fortaleza/ Ceará con más de 2 millones de habitantes), es abastecer las ciudades afectadas con los famosos camiones de agua (carros-pipa) o, en el caso concreto de Campina Grande, con una cañería superficial desde Pernambuco, estado vecino ya alcanzado por el agua de la transposição. (Agradezco las informaciones actuales de primera mano y los comentarios constructivos, sobre este y otros asuntos aquí referidos, de Durval Muniz de Albuquerque Jr./ UFRN, Roberto Marques/ URCA y Gilvan Alves Ramos/ EMBRAPA.)

${ }^{20}$ Para dar un ejemplo, Ramos (12/12/2016) menciona incidentes en los perímetros de irrigación en Petrolina/ Pernambuco y Juazeiro/ Bahia. 
canales y la restauración de los conductos defectuosos, incluyendo la cañería urbana - una fuente de constante desperdicio de agua que no se debería subestimar (Furtado, 2/2/2005a: 8; id., 2/2/2005b: 9, citando a Nankani, 6/3/2001).

Así mismo, João Suassuna, ingeniero agrónomo y analista de la Fundação Joaquim Nabuco, advirtió del impacto ambiental incalculable y ofreció soluciones con las reservas hídricas ya existentes en la zona de sequía. Aparte del agua de las desembocaduras de los ríos regionales, que suma los 58 mil millones de litros cúbicos, el semiárido nordestino cuenta con más de 70.000 presas, de una capacidad total de 37 mil millones de metros cúbicos ("Do rio para o sertão", 2005: 23). ${ }^{21}$ Estas masas de agua no se aprovechan como sería de desear, siendo la evaporación, que llega al 70\%, un gran problema y porque su beneficio social es muy limitado, ya que apenas un $20 \%$ de las presas está conectado a una red de distribución (Duarte, 2002: 25-26). Por lo tanto, Suassuna también propuso mejorar la conservación del agua en los embalses y proveer a la región de un sistema de distribución amplio y equitativo ("Do rio para o sertão", 2005: 23). Mientras que los críticos del trasvase de aguas del río São Francisco anteponen este tipo de iniciativas descentralizadas a la centralización de los recursos hídricos inherente a los megaproyectos, los partidarios de la transposição argumentan que ésta - dada la inmensa falta de agua - es una condición sine qua non para cualquier modelo posterior de descentralización (cf. Schmitt, 2013: 253).

\section{Instrumentalización política de la sequía}

Volviendo a la comparación entre Epitácio Pessoa y Luiz Inácio Lula da Silva, primero es necesario constatar que no se trata de comparar las dos personas en sí, ya que provienen de momentos históricos muy diferentes y de contextos sociales aún más divergentes, incluso contrarios. Epitácio Pessoa era un oligarca, llevando la política de su provincia natal Paraíba con autoritarismo absoluto durante 15 años y luchando con vehemencia contra el movimiento obrero durante su mandato al frente del país. Medio siglo más tarde, Lula da Silva, en cambio, surgió justamente del movimiento obrero. Lo que se compara en el mencionado reportaje del Diário de Pernambuco de 2010 es la política hidráulica de los dos presidentes de origen nordestino, alabando sus esfuerzos singulares para la región de la sequía (Santiago, 2010). Tal comparación - dejando de lado el hecho de que el Nordeste, sus habitantes y sus desafíos no son los mismos hoy que hace cien años - se puede considerar pertinente sólo en el sentido de que en ambos casos, a través de proyectos

\footnotetext{
${ }^{21}$ Duarte (2002: 26) habla de 100.000 presas con 25 mil millones de metros cúbicos.
} 
hidráulicos de una envergadura jamás vista en Brasil, se creó una gran expectativa de un cambio de paradigma y de una mejora sustancial para los nordestinos. Una cuestión distinta es si los elogios son justificados, si los dos presidentes respondieron a las esperanzas. Los partidarios de Epitácio Pessoa siempre podían argumentar que si no hubiera sido por la cancelación abrupta y casi completa de las obras por parte del siguiente presidente, los planes habrían dado fruto. La pregunta a quien habrían dado fruto, nos lleva al hecho de que Epitácio Pessoa aprovechó la política de la sequía para el sustento del poder oligárquico que a su vez era el fundamento de su propio dominio:

(...) his efforts on behalf of drought relief (...) testified to the strength of elite family power throughout the region. (Lewin, 1987: 309)22

(...) o horizonte de Epitácio também era oligárquico e as obras de açudagem, as estradas, os poços, consolidavam os redutos de seus correligionários, e, por extensão, o seu grupo, que constitui a oligarquia mais sólida e duradoura no controle do aparato de Estado na Paraíba. Neste jogo, oficial, quem perde é o povo. (Silveira, 1993: 11)

Lula da Silva y sobre todo su sucesora del Partido de los Trabajadores, Dilma Rousseff, también se beneficiaron políticamente del programa hidráulico, pero ya en el sentido democrático. En las elecciones presidenciales de 2010, la proporción de votos para Rousseff fue especialmente alta en las regiones de la construcción de los canales (75-95\%; Bresciani/ Pedrosa, 3/12/2011). También para su reelección en octubre de 2014, por el escaso margen del 51,6\%, el apoyo de los nordestinos fue decisivo (Rousseff consiguió el $72 \%$ de los votos en todo el Nordeste), ${ }^{23}$ como la propia presidenta afirmó:

Fui eleita por 54 milhões de votos. A maioria deles eu conquistei aqui no Nordeste. Eu nunca esqueci isso e nunca vou esquecer (...) o povo do Nordeste, proporcionalmente, foi quem mais votou em mim (...). (Portal Brasil, 6/5/2016)

Con estas palabras Dilma Rousseff expresó su gratitud hacia sus votantes en el Nordeste, visitando el Eixo Norte del Projeto de Integração do Rio São Francisco, poco antes de ser

\footnotetext{
${ }^{22}$ Cf. también ib.: 165, 212, 308-309, 320-322.

${ }^{23}$ Para una exposición diferenciada véase Toledo, 28/10/2014.
} 
destituida por la maniobra del impeachment. En cuanto al futuro de las obras hidráulicas en el Nordeste y su subsecuente uso, la ambigua destitución de Rousseff ha llevado a una situación parecida a la de la salida de Epitácio Pessoa del Palacio de Catete en 1922. Igual que al final del mandato de Pessoa, muchos habitantes de la zona de la sequía llegaron a preguntarse qué continuidad daría el nuevo gobierno a la política hidráulica (Portal Brasil, 9/5/2016a). ${ }^{24}$ Si ya antes los escépticos temían que la mayor parte del riego agrícola sería acaparada por un pequeño círculo de exportadores agroindustriales, las preocupaciones generales acerca del proyecto de Integração do São Francisco no dejaron de crecer desde que la presidenta fue privada de su cargo. No sorprende que Rousseff también alimentara esta desconfianza hacia sus enemigos políticos:

(...) esse é um golpe que não é só contra a democracia, é contra os programas sociais, contra os compromissos que nós assumimos ao longo desses 13 anos que assumimos o Brasil (...). (Portal Brasil, 6/5/2016)

Al final, ¿seguirá la política hidráulica estando al servicio de una élite económico-agraria como en la época de Epitácio Pessoa? ¿O se ha encaminado irreversiblemente hacia un "desenvolvimento regional sustentável", beneficiando al conjunto de la población y primordialmente a las familias, como sigue confirmando la presentación oficial del gobierno (Ministério da Integração Nacional, 2016)?

\section{La "convivencia con el semiárido", más allá del eslogan político}

Al comienzo de la presidencia de Luiz Inácio Lula da Silva se esperaba un auge de apoyo gubernamental al concepto de la 'convivência com o semiárido', una alternativa a metas meramente comerciales, con cultivos y una cultura ambiental y social sostenibles, adaptados a los recursos hídricos, al medio en general y a las relaciones sociales. El ámbito más propicio para la 'convivência' es la agricultura familiar porque conserva la naturaleza, emplea más trabajadores e incluso es más eficiente que la agroindustria, como demuestran los resultados respectivos en Brasil. Los programas sociales instituidos por el gobierno Lula da Silva, por ejemplo Fome Zero y Bolsa Família, ${ }^{25}$ aliviaron la vida de los menos

\footnotetext{
${ }^{24}$ Un mes antes de que se terminara la presidencia de Epitácio Pessoa, los periódicos informaban sobre la „duvida atroz que ora atormenta os habitantes daquella região, devido aos beatos de que o futuro govêrno suspenderia as obras contra as sêccas“"(Queiroz, 15/10/1922: 1).

${ }^{25}$ Otros son el Programa de Aquisição de Alimentos (PAA), el Programa de Auxílio Emergencial Financeiro (BolsaEstiagem) y el Programa Minha Casa Minha Vida (PMCMV).
} 
favorecidos. La repartición de tierras mitigó los conflictos en el campo, pero al final no se realizó la reforma agraria esperada por grupos sociales como el Movimento dos Trabalhadores Rurais Sem Terra (MST). La extensión de la industria agraria incluso neutralizó y contrarrestó muchos de los efectos positivos de la incipiente reestructuración de la propiedad rural. ${ }^{26}$

La facilitación de cisternas, que disminuyen la dependencia de los pequeños campesinos del suministro externo de agua, ofrece otro ejemplo de como un plan institucional diseñado para auxiliar a la población más desamparada, a posteriori puede sufrir alteraciones desventajosas para los destinatarios. En 2003, la asociación no gubernamental Articulação no Semiárido Brasileiro (ASA) proyectó la construcción de “Um milhão de cisternas" dentro de cinco años. Aunque el programa consiguió financiación del gobierno federal y una muy buena acogida de los habitantes de la zona de sequía, después de nueve años, con unas 500.000 cisternas construidas, apenas se había alcanzado la mitad de la meta establecida. Según el Cadastro Único del gobierno federal, 738.800 familias en ocho estados del Nordeste y Minas Gerais necesitaban una cisterna para el consumo básico. Ante esta situación, en 2011 el gobierno decidió renunciar a las cisternas de albañilería de la ASA y optar por las de polietileno para acelerar el proceso e instalar 300.000 cisternas hasta el final del primer mandato de Dilma Rousseff en 2014. (Dantas/ Paulino, 2013; Aderaldo, 22/3/2012) Además del argumento de la rapidez de colocación, el responsable Ministério da Integração Nacional alegaba que las cisternas de polietileno serían más económicas, más duraderas y de tecnología "limpa e ecológica" (Madeiro, $12 / 11 / 2015) \cdot{ }^{27}$

Los integrantes civiles del programa “Um milhão de cisternas” mostraron su gran decepción con el gobierno por la ruptura de la colaboración, incluso se quedaron perplejos ya que, desde su punto de vista, las "cisternas de plástico" no mostraban ventajas reales en comparación con el modelo de albañilería. No resultaban más económicas ( $\mathrm{R} \$ 5090$ frente a unos $R$ \$ 2200), hubo muchos retrasos en la instalación y - a veces después de pocos meses - problemas materiales como deformaciones, anticipando que el polietileno sería menos resistente al intenso sol del sertão, calentando excesivamente el agua y contaminando el medio ambiente. (Aderaldo, 22/3/2012; Dantas/ Paulino, 2013; Madeiro,

\footnotetext{
${ }^{26}$ Cf. Schmitt, 2013: 339-341, 354-357. Ariovaldo Umbelino de Oliveira (USP) habla de "não reforma agrária" ("não fazê-la nas áreas de domínio do agribusiness e, fazê-la apenas nas áreas onde ela possa 'ajudar' o agribusiness", Oliveira, A. U., 2011: 8) y de "contra reforma agrária" (“acoplada à expansão do agribusiness no Brasil”, ib.: 1).

${ }^{27}$ El Ministério da Integração Nacional fue incluido en el programa Água para Todos en 2011. Anteriormente, el Ministério do Desenvolvimento Social e Combate à Fome (MDS) era el único ente estatal en financiar la construcción de las cisternas por parte de organizaciones no gubernamentales, vinculadas a la Associação Programa Um Milhão de Cisternas (AP1MC) de la ASA (Dantas/ Paulino, 2013; Aderaldo, 22/3/2012).
} 
12/11/2015; AS-PTA, 27/3/2013) Aparte de estos argumentos técnicos y ecológicos, se criticaba que el nuevo sistema rompería "toda a lógica de mobilização social" (Adriano Leitão, coordinador de proyectos de Cáritas/ Crateús, citado en: Nogueira, 1/7/2015). Al contrario de la distribución central de las cisternas de polietileno, el programa concebido por la ASA es un proceso descentrado basado en la participación de las comunidades. Se beneficia la economía local, adquiriendo todo el material necesario in situ, formando a las personas en la construcción y manutención de las cisternas y en el manejo responsable del agua. Es un paso hacia la autonomía de los usuarios, también para resolver cualquier problema y reparación posteriores. En cambio, cuando las cisternas de plástico se deformen o tengan otros defectos, la comunidad dependerá del aparato burocrático para que éste evalúe la situación y facilite arreglos o sustituciones. Por eso, se temía que las cisternas de polietileno no sólo llevaran a eventuales montañas de basura de plástico, sino que abrieran la puerta al clientelismo, con altas ganancias para los intermediarios políticos y los grandes fabricantes de las cisternas. (Ib.; AS-PTA, 27/3/2013) El descontento se vio reflejado en el discurso de los activistas, lamentando que "o governo persista com muitas ações próprias da velha política de combate à seca" (Naidson de Quintela Baptista [sic] ${ }^{28}$, coordinación de ASA/ Bahia y presidencia de AP1MC, citado en: Abong, 13/12/2011) o que vuelva "toda aquela história da indústria da seca" (Leitão, citado en: Nogueira, 1/7/2015). Mientras que antes de 2003 parecía que las políticas estatales "eram pensadas e formuladas para garantir uma relação de subalternidade" (Neidson Batista [sic], ASA/ Bahia, citado en: Portal Brasil, 9/5/2016b), el proyecto “Um milhão de cisternas” mostró el camino hacia una "democratização da água" (Portal Brasil, 9/5/2016b). Para defender este avance, a finales de 2011 y en 2012, se organizaron grandes manifestaciones contra el cese de la cooperación entre el gobierno y las asociaciones civiles. Finalmente Brasília decidió invertir de nuevo en las cisternas de albañilería. Además de las 300.000 cisternas de plástico, se construirían 450.000 de hormigón. Actualmente, según informaciones oficiales, se han construido 1,2 millones de cisternas desde 2003, con una capacidad total de 20,1 mil millones de litros. (Dantas/ Paulino, 2013; Plataformaosc, 2016; Portal Brasil, 9/5/2016b)

Tanto las dudas acerca de los proyectos hidráulicos como los contratiempos de la esperada reforma agraria y del programa “Um milhão de cisternas” denuncian que el antiguo concepto de la 'lucha contra la sequía' - en vez de la 'convivencia con la sequía' y la tradición de políticas paternalistas, que recuerdan los tiempos de Epitácio Pessoa, aún no están del todo superados. Una decisión política - sin mencionar un cambio de gobierno

\footnotetext{
${ }^{28}$ En los diversos artículos se encuentra una gran variedad de formas de escribir este nombre y apellidos, entre ellas Naidison de Quintella Baptista.
} 
- pueden alterar íntegramente los objetivos de la política hidráulica. ${ }^{29}$ Afortunadamente, la meta de "Um milhão de cisternas" se ha alcanzado y el beneficio de esta medida descentralizadora es irreversible, por lo menos en el caso de las cisternas de albañilería que ya no dependen de asistencia externa. Sin embargo, las circunstancias son diferentes en relación a megaproyectos centralizadores, sea en el período de Epitácio Pessoa, sea en la actualidad. Lo que al final cuenta no son solamente las obras de ingeniería, sino el uso que se le da al agua. Su distribución siempre supone resoluciones políticas, por lo cual en un momento dado el poder sobre el agua estará concentrado en pocas manos. Según la corriente política, se puede fomentar la conservación del medio ambiente y favorecer a la mayoría de la población o dar preferencia al modelo de explotación económica en detrimento del bien común.

Romper con las políticas paternalistas y centralizadas significa darle a la población las herramientas necesarias para hacer frente a la falta de recursos hídricos. En el área rural, las cisternas de albañilería son una parte esencial de esta solución. En las grandes urbes, la situación es mucho más compleja y requiere una intervención e inversiones estatales cuantiosas lo que, sin embargo, no resta importancia a las soluciones descentralizadas como el saneamiento de los conductos de agua por parte de los municipios y el manejo y uso responsables de los recursos acuáticos por parte del conjunto de la población y especialmente de la industria agraria. Mientras que los gobiernos no regulen y controlen con vigor y visión de futuro la utilización del agua en las actividades comerciales, no se puede esperar del sistema capitalista un comportamiento sostenible a largo plazo, ni siquiera en regiones con recursos hídricos extremamente limitados, que son ya y serán cada vez más amplias. Por lo demás, ni el problema de la sequía ni mucho menos el problema de la desigualdad social se limitan al Nordeste. ${ }^{30}$

La comparación aquí reproducida entre Epitácio Pessoa y Lula da Silva no se refiere, como ya se ha indicado, a los dos políticos en si, sino a su política hidráulica, la

\footnotetext{
${ }^{29}$ Cabe recordar que en el año 1964, con el golpe militar, terminó otra ilusión de mejorar la situación en el Nordeste, reforma agraria y participación de la sociedad civil incluidas. Según Ramos (12/12/2016), para identificar las principales propuestas para la región de la sequía, sobre todo respecto a las cuestiones sociales y ecológicas, hay que tener en cuenta el documento "Uma política de desenvolvimento econômico para o Nordeste" del Grupo de Trabalho para o Desenvolvimento do Nordeste (GTDN), liderado por Celso Furtado, "peça preliminar à concepção e criação da SUDENE", en 1959 (SUDENE, 1967: 4). Acerca de las dificultades para realizar las reformas véanse Carvalho, 1988: 226-233 y Furtado, 1998: 66-72.

${ }^{30}$ Por una parte, muchos nordestinos que pueblan las favelas del Sudeste - y obviamente no sólo ellos - siguen viviendo los mismos problemas de exclusión social y además están muy conectados a las dificultades de su región de origen. Por otra parte, el problema de la sequía - que antes de la 'invención' del Nordeste (Albuquerque Jr., 1999), hace poco más de cien años, fue compartido por Norte y Sul (cf. Bourbon, 1/6/1877: 2; Osório, 27/6/1877: 249) -, con el agravamiento de la situación climática global dejó de ser 'monopolio' del Nordeste. Para más información, véase las aportaciones de los conferenciantes del congreso "O Brasil e a água" que abarcan las otras regiones brasileñas, incluyendo el Sudeste.
} 
que en el caso de Lula da Silva engloba la continuación por parte de su sucesora Dilma Rousseff. El hecho de que Pessoa por un lado y Lula/ Rousseff por el otro se caractericen por diferencias sociales y políticas tan marcadas, siendo además las circunstancias y necesidades de sus medidas tan distintas y distantes en el tiempo, ofrece la oportunidad de concentrarse en la esencia obvia de los megaproyectos. Independientemente de las finalidades iniciales y del bando político de sus iniciadores, los megaproyectos - por su control centralizado - se convierten en un instrumento de manipulación a merced de los que ostentan el poder. La experiencia global, con los ejemplos más destacados de las últimas décadas situados en los países emergentes y en vías de desarrollo, ha mostrado la gran carencia de equidad social y compromiso ambiental debido a los respectivos sistemas políticos (WBGU, 1998: 175; Fröhlich, 19/6/2006: 32-37). ${ }^{31}$ En China, la India y África, los megaproyectos y la resultante agricultura de regadío favorecieron a los grandes agricultores, mientras que los pequeños campesinos y comunidades marginadas salieron perjudicados, privados de participar en la planificación, la toma de decisiones y los beneficios. La creciente disparidad económica y social no se vio compensada por la aparición de nuevos empleos en la agroindustria. Los cálculos oficiales de coste-beneficio a menudo ocultan las desventajas, exaltando las ventajas. Además, la percepción de las metas varía dentro y fuera de los países. En el caso de la presa de las Tres Gargantas en el río Yangtsé, por parte de la administración se resalta la absoluta necesidad de la prevención de inundaciones para amparar a la población del valle entre Yichang y Shanghai, en tanto que la opinión pública internacional percibe sobre todo el objetivo de la generación de energía. En este punto surge un 'dilema' de los grupos medioambientales que, en principio, promueven las energías renovables, y sin embargo rechazan las grandes obras hidroeléctricas por las consecuencias ecológicas locales y regionales. (WBGU, 1998: $156,176,181-183,185$.) Ya que el impacto nocivo de los megaproyectos hidrológicos, tanto ecológica como económicamente, suele ser significativo y siempre difícil de prever y controlar, incluso en China los proyectos descentralizados están ganando más aceptación y se dice que "los tiempos de las presas gigantescas realmente han pasado" (Zhou Xizhou, Director de la consultora de energía Cambridge Energy Research Associates/ Pekín, citado por Geinitz, 18/6/2010). ${ }^{32}$ Una de las razones de la mayor oposición contra los megaproyectos en China ha sido el traslado forzoso de millones de habitantes (WBGU, 1998: 181-183).

\footnotetext{
${ }^{31}$ Para más referencias véase Neufert, 2015: 403-404. La evolución política de los últimos años no permite descartar problemas similares en el mundo occidental.

${ }^{32}$ El ejemplo más escandaloso de política hidráulica es probablemente el trasvase de agua de los ríos Amu Daria y Sir Daria para cultivos de regadío, principalmente el algodón, con el resultado de la casi completa devastación del ecosistema del Mar de Aral (WBGU, 1998: 184; Noronha, 16/3/2017).
} 
Asimismo, en el Nordeste brasileño, se ha formado resistencia contra las obras hidráulicas por causa del desalojo de millares de familias, entre ellas de comunidades indígenas y quilombolas. $^{33}$

El Banco Mundial, por su parte, desde la última década del siglo XX se ha distanciado de su antigua práctica de ayudas a megaproyectos y exige la completa incorporación del coste social y ambiental en los estudios preliminares de viabilidad (WBGU, 1998: 182). En cuanto al Projeto de Integração do Rio São Francisco, el Banco Mundial lo desaconsejó por los mencionados motivos ecológicos y sociales, tanto en un informe confidencial al entonces presidente Fernando Henrique Cardoso en 2001 como a su sucesor Luiz Inácio Lula da Silva en 2003 y 2004. En su momento, ninguno de los dos presidentes hizo público el análisis del Banco Mundial, pero Lula da Silva, en contraposición a las recomendaciones, lanzó una importante campaña de promoción. (Furtado, 2/2/2005a: 8.) A partir de ahí, la innegable urgencia de encontrar una solución al abastecimiento de los núcleos urbanos ha llegado a ser el argumento emblemático e irrebatible a favor del trasvase de aguas del río São Francisco, utilizado por el gobierno y los partidarios del proyecto en general. En cambio, los detractores nacionales e internacionales no han dejado de recordar los incalculables efectos medioambientales y la cuestión social de la distribución del agua destinada a la agricultura. En el propio Nordeste brasileño, algunos movimientos sociales tenían la esperanza de que a través de su participación en los llamados comitês de bacias podrían influir en la elaboración de infraestructuras hídricas descentralizadas y la democratización del acceso al agua. Sin embargo, viendo sus intentos frustrados, muchos salieron de los comités para no legitimar la política estatal que secundaba la preferencia por la comercialización agroindustrial. Con asesores profesionales ocupando las vacantes en los comités, éstos parecen haberse vuelto más homogéneos y más eficientes, por lo menos desde el punto de vista de la administración central (cf. Schmitt, 2013: 326-328).

La construcción material de los proyectos hidrológicos siempre se acompaña de una construcción discursiva de un proyecto ideológico. Epitácio Pessoa sabía como vestir su política económica de la sequía, de clara orientación oligárquica, con el ropaje de una labor humanitaria. A través de su discurso conseguía movilizar a la población del Nordeste, transmitiéndoles a todos, particularmente a los pequeños campesinos, la ilusión de que estaban trabajando en las grandes obras para luego aprovechar los nuevos recursos hídricos y labrarse un porvenir mejor (Gurjão, 1994: 49, refiriéndose a Barbosa, 1935: 2122). La procedencia del presidente del Nordeste legitimaba su discurso sobre la región y, por ende, Pessoa disfrutaba de una gran confianza entre los habitantes del polígono de la

\footnotetext{
${ }^{33}$ Acerca de las protestas en el Baixio das Palmeiras véase Maria, Alana, 9/8/2016; véase también Movimento dos
} 
sequía, quienes estaban más que dispuestos a abrazar la solución que se les ofrecía para que sus problemas se resolvieran definitivamente. El discurso y la actuación de Pessoa fueron tan convincentes que él sigue recibiendo elogios hasta hoy, a pesar de las críticas fundamentadas por parte de contemporáneos más progresistas y a pesar de que las grandes obras hidráulicas de su gobierno dejaron un balance de corrupción y aprovechamiento político sin que se produjeran los beneficios prometidos a los nordestinos.

Igual que en el caso de Epitácio Pessoa, la política hidráulica de otro presidente nordestino, Lula da Silva, y de su sucesora Dilma Rousseff se debe juzgar imparcialmente, sin darles alabanzas anticipadas por su origen o signo político, ni restarles credibilidad por cuestiones ajenas al proyecto. Lo que cuenta son la realización, la ejecución y el alcance efectivo, aun cuando las intenciones iniciales hayan sido distintas e incluso aunque la utilización última de los recursos hídricos ya no esté en manos de los que iniciaron el proyecto. En otras palabras: el mérito no se gana llevando el agua a grandes distancias sino haciéndola llegar por las vías cortas a quien más la necesite, sea en las ciudades, sea en el campo. Aún queda por evaluar los resultados finales del trasvase de aguas del río São Francisco, una vez que los tramos centrales se terminen, probablemente en 2017. La situación política, de momento de gran incertidumbre, siempre repercutirá en el desempeño del proyecto y el uso equitativo y sostenible del agua. Lo que el ejemplo de "Um milhão de cisternas" demostró es que la implicación de la sociedad civil es determinante para no volver a la instrumentalización de la sequía y para impedir que el agua siga moviendo los molinos del poder.

\section{Bibliografía}

Abong - Organizações em defesa dos direitos e bens comuns. 13/12/2011. Governo Federal rompe com a ASA Brasil e regride na política de construção de cisternas no semiárido. www.abong.org.br/noticias.php?id=4678.

Ab'Saber, Aziz. 2006. “A transposição de águas do São Francisco: análise crítica”. Revista USP (São $\quad$ Paulo) $70 \quad$ (junio/ agosto): 6-13. http://www.revistas.usp.br/revusp/article/view/13527.

Ab'Saber, Aziz. 22/3/2011. "A quem serve a transposição das águas do São Francisco". CartaCapital (São Paulo). http://www.cartacapital.com.br/sociedade/a-quem-serve-atransposicao-das-aguas-do-sao-francisco-2/. 
Aderaldo, Daniel. 22/3/2012. "Trabalhadores protestam contra cisternas de plástico no Dia Mundial da Água". Último Segundo. http://ultimosegundo.ig.com.br/brasil/ce/trabalhadores-protestam-contra-cisternas-deplastico-no-dia-mund/n1597704661331.html.

Aguiar, Manuel Pinto de. 1983. Nordeste - o drama das secas. Rio de Janeiro: Civilização Brasileira.

Albuquerque Júnior, Durval Muniz de. 1988. Falas de astúcia e de angústia: a seca no imaginário nordestino - de problema à solução (1877-1922) (Dissertação de mestrado em história, inédita). Campinas: Unicamp.

Id. 1999. A invenção do Nordeste e outras artes (Série Estudos e pesquisas, v. 104; originalmente tesis doctoral: O engenho antimoderno. Campinas: Unicamp. 1994). Recife: Massangana/ São Paulo: Cortez.

Araripe, Tristão Alencar (Ceará). 27/6/1877. Anais da Câmara dos Deputados. Rio de Janeiro. Arquivo Nacional (Rio de Janeiro).

AS-PTA - Agricultura Familiar e Agroecologia. 27/3/2013. Cisternas de plástico chegam à Paraíba e preocupam famílias e organizações de agricultores da região do Polo da Borborema. http://aspta.org.br/2013/03/cisternas-de-plastico-chegam-a-paraiba-e-preocupam-familiase-organizacoes-de-agricultores-da-regiao-do-polo-da-borborema.

Barbosa, Orris. 1935. Secca de 32 (Impressões sobre a crise nordestina). Rio de Janeiro: Adersen-Editores.

Barbosa, P.e Florentino. 19/4/1922. "A redempção do nordéste". A União. Diario official do Estado (Parahyba): 1. Arquivo Maurílio Almeida (João Pessoa).

Batista Neto, José. 1986. Como uma luneta invertida (intervenção do Estado no semi-árido nordestino através do discurso ideológico da IOCS/IFOCS) (Dissertação de mestrado em história, inédita), Recife: Universidade Federal de Pernambuco.

Borges, Dain Edward. 1992. The family in Bahia, Brazil, 1870-1945. Stanford: Stanford University Press.

Borges, Frederico (Ceará). 13/7/1920 y 21/12/1920. Anais da Câmara dos Deputados. Rio de Janeiro. Arquivo Nacional. 
Bouchardt, Jonny. 23/5/1915 (1 ${ }^{\text {a }}$ parte) y 25/5/1915 (2a parte). "Solução radical e scientifica do problema das sêccas. Meios a empregar e resultados provaveis". A União. Diario official do Estado (Parahyba): 1-2. Arquivo Maurílio Almeida (João Pessoa).

Bourbon, Isabel Cristina Leopoldina Augusta Miguela Gabriela Rafaela Gonzaga de Bragança e. 1/6/1877. "Falla da Princeza Imperial Regente Izabel". Anais do Senado. Rio de Janeiro.

Bresciani, Eduardo/ Pedrosa, Wilson. 3/12/2011. “Governo abandona transposição do São Francisco após eleição de Dilma". Estadão (São Paulo). http://politica.estadao.com.br/noticias/geral,governo-abandona-transposicao-do-saofrancisco-apos-eleicao-de-dilma,806292.

Carvalho, Otamar de. 1988. A economia política do Nordeste. Secas, irrigação e desenvolvimento. Rio de Janeiro: Campus/ Brasília: ABID-Associação Brasileira de Irrigação e Drenagem.

Castro, Iná Elias de. 1992. O mito da necessidade. Discurso e prática do regionalismo nordestino. Rio de Janeiro: Bertrand Brasil.

Id. 1996. "Seca versus seca. Novos interesses, novos territórios, novos discursos no Nordeste". Eds. id./ Gomes, Paulo Cesar da Costa/ Corrêa, Roberto Lobato. Brasil: questões atuais da reorganização do território, 283-323. Rio de Janeiro: Bertrand Brasil.

CEPAL (Comisión Económica para América Latina y el Caribe)/ FAO (Organización de las Naciones Unidas para la Agricultura y la Alimentación)/ IICA (Instituto Interamericano de Cooperación para la Agricultura). 2013. "Cuadro 6. Pobreza, pobreza extrema e ingresos medios". En: Perspectivas de la agricultura y del desarrollo rural en las Américas: una mirada hacia América Latina y el Caribe: 2014, p. 216. San José/ Costa Rica: IICA. http://www.fao.org/docrep/019/i3702s/i3702s.pdf.

CPDOC (Centro de Pesquisa e Documentação de História Contemporânea do Brasil)/ FGV (Fundação Getúlio Vargas). A era Vargas: Anos 20. Questão social. http://cpdoc.fgv.br/producao/dossies/AEraVargas1/anos20/QuestaoSocial.

Cruz, Valdo/ Amora, Dimmi. 12/7/2016. "Para acelerar obra do São Francisco, governo libera mais verbas". Folha de S. Paulo. http://www1.folha.uol.com.br.

Dantas, Mariana/ Paulino, Wladmir. 2013. "Cisternas da discórdia. Em meio à maior seca dos últimos 40 anos, distribuição de reservatórios de polietileno aos sertanejos sofre atrasos, críticas e até denúncias de corrupção". NE10. http://especiais.ne10.uol.com.br/cisternas-da-discordia/index.html. 
“Do rio para o sertão". 2005. Nossa História (Rio de Janeiro: Biblioteca Nacional) 2 (18: abril), 22-24.

Duarte, Renato. 2002. Do desastre natural à calamidade pública: a seca de 1998-1999. Recife: Fundação Joaquim Nabuco/ Assembléia Legislativa do Estado de Pernambuco.

Espinola, Toscano. 6/7/1952. “Epitacio Pessôa. Conferência realizada pelo Desembargador Toscano Espinola, na Casa da Parahyba, no dia da data natalícia do eminente estadista brasileiro" (2a parte). Jornal do Comercio (Rio de Janeiro). Arquivo do Instituto Histórico Geográfico Brasileiro/ IHGB. Lata 738, pasta 14, doc. 16.

Fernandes, Vivian. 23/3/2012. “Transposição do rio São Francisco custa R\$ 3,4 bi a mais que o previsto". Brasil de Fato. http://www.brasildefato.com.br/node/9137.

Ferreira, Lúcia de Fátima Guerra. 1993. Raízes da indústria da seca: o caso da Paraíba. João Pessoa: Centro de Ciências humanas, letras e artes/ Editora Universitária.

Fröhlich, Christiane. 19/6/2006. "Zur Rolle der Ressource Wasser in Konflikten". Ed. Bundeszentrale für Politische Bildung. Aus Politik und Zeitgeschichte 25 (2006): 32-37. http://www.bpb.de/apuz/29688/wasser.

Furtado, Bernardino. 2/2/2005a. "Banco Mundial rejeita transposição". Estado de Minas (Belo Horizonte): 8.

Id. 2/2/2005b. “[Transposição:] Baixo impacto contra a pobreza”. Estado de Minas: 9.

Furtado, Celso. 1998. Seca e poder: entrevista com Celso Furtado (entrevistadores: Maria da Conceição Tavares, Manuel Correia de Andrade, Raimundo Pereira). São Paulo: Editora Fundação Perseu Abramo.

Gabaglia, Laurita Pessoa Raja. 1966. “A figura humana de Epitácio Pessoa”. Revista do Instituto Histórico e Geográfico Brasileiro (Rio de Janeiro: Departamento de Imprensa Nacional) 268 (julio-sept. 1965): 65-82.

Geinitz, Christian. 18/6/2010. "Staudämme: China setzt auf riesige Wasserkraftwerke." Frankfurter Allgemeine Zeitung. http://www.faz.net/aktuell/wirtschaft/unternehmen/staudaemme-china-setzt-auf-riesigewasserkraftwerke-1638275.html.

Gomes, Alfredo Macedo. 1998. Imaginário social da seca. Suas implicações para a mudança social. Recife: Fundação Joaquim Nabuco/ Editora Massangana. 
Gomes, Gustavo Maia. 2001. Velhas secas em novos sertões: continuidade e mudanças na economia do Semi-Árido e dos Cerrados nordestinos. Brasília: IPEA.

Gurjão, Eliete de Queiróz. 1994. Morte e vida das oligarquias, Paraíba (1889-1945). João Pessoa: Editora Universitária/ UFPb.

Haesbaert, Rogério. 1997. Des-territorialização e identidade. A rede "gaúcha" no Nordeste, Niterói: Editora da Universidade Federal Fluminense.

Lacerda, Maurício Paiva de (Rio de Janeiro). 13/7/1920. Anais da Câmara dos Deputados. Rio de Janeiro. Arquivo Nacional.

Id. 13/7/1917, 14/7/1917 y 18/7/1917. Diário do Congresso Nacional. Rio de Janeiro. Arquivo do Instituto Histórico Geográfico Brasileiro/ IHGB.

Lamartine, Juvenal (Rio Grande do Norte). 23/11/1915. Anais da Câmara dos Deputados. Rio de Janeiro. Arquivo Nacional.

Lessa, Carlos. 20/6/2005. "Nordeste poderá ser solução do Brasil”. Valor econômico (São Paulo).

Id. 6/7/2005. "O sertão vai virar mar". Valor econômico (São Paulo).

Lewin, Linda. 1987. Politics and parentela in Paraíba. A case study of family-based oligarchy in Brazil. Princeton: Princeton University Press.

Madeiro, Carlos. 12/11/2015. “Incêndio destrói 40 cisternas de plástico do governo federal no Piauí". BOL Notícias. http://noticias.bol.uol.com.br/ultimasnoticias/brasil/2015/11/12/incendio-destroi-40-cisternas-de-plastico-do-governo-federal-nopiaui.htm.

Maria, Alana. 9/8/2016. “O Baixio resiste. O distrito rural Baixio das Palmeiras protesta e contesta a lógica da maior e mais ambiciosa obras hídrica do estado, o Cinturão das Águas do Ceará." Cariri Revista (Juazeiro do Norte/ Ceará). http://caririrevista.com.br/o-baixioresiste.

Melo, Fernando. 2005. Epitácio Pessoa. Uma biografia. João Pessoa: Idéia.

Mendes, Mauricio Matos. 2009. A experiência anarquista no Brasil: reflexos das greves de 1917 na Câmara dos Deputados (Monografia de Pósgraduação no Centro de Formação da Câmara dos Deputados/ Cefor). Brasília: Câmara dos Deputados. 
Ministério da Integração Nacional. 16/3/2012. “Integração Nacional vistoria obras do Projeto São Francisco em Custódia (PE)". Portal Brasil (Brasília). http://www.brasil.gov.br/infraestrutura/2012/03/integracao-nacional-vistoria-obras-doprojeto-sao-francisco-em-custodia-pe.

Id. 23/2/2015. Projeto Rio São Francisco. O que é o projeto? www.integracao.gov.br.

Id. 2016. Projeto de Integração do Rio São Francisco. O que é o projeto? Entenda os detalhes/ Vazão e uso da água. www.mi.gov.br/projeto-sao-francisco.

Movimento dos Atingidos por Barragens (Coordenação Nacional, São Paulo). 20/3/2017. “Transposição do São Francisco: que as águas sirvam à vida!" Movimento dos Trabalhadores Rurais Sem Terra. http://www.mst.org.br/2017/03/20/transposicao-do-sao-francisco-que-asaguas-sirvam-a-vida.html.

Nankani, Gobind T. (director del Banco Mundial en Brasil). 6/3/2001. Escrito al Ministro de Integración Fernando Bezerra. Citado en: Furtado, 2/2/2005b: 9.

Nascimento, Nicanor (São Paulo; diputado para el Distrito Federal). 14/7/1917. Diário do Congresso Nacional. Rio de Janeiro. Arquivo do Instituto Histórico Geográfico Brasileiro/ IHGB (Rio de Janeiro).

Id. 9/7/1920. Anais da Câmara dos Deputados. Rio de Janeiro. Arquivo Nacional.

Neufert, Tim. 2015. Die Macht der Dürre. Wasser und Politik in Brasilien in der Zeit von Epitácio Pessoa (1877-1930) ("El poder de la sequía. Agua y política en Brasil en los tiempos de Epitácio Pessoa”. Tesis doctoral. Universidad de Colonia, 2012). Köln: Böhlau Verlag.

Neves, Frederico de Castro. 1994. Imagens do Nordeste: a construção da memória regional (Coleção Teses Cearenses). Fortaleza: SECULT.

Id. 1995. “Curral dos bárbaros: os campos de concentração no Ceará (1915 e 1932)”. Revista Brasileira de História (São Paulo) 15 (29): 93-122.

Nóbrega, Apolonio. 1950. História republicana da Paraíba. João Pessoa: Imprensa Oficial. Citado por Ferreira, 1993: 105.

Nogueira, Edwirges. 1/7/2015. "Entidades criticam novo modelo de cisternas feitas de plástico". Agência Brasil - EBC. http://agenciabrasil.ebc.com.br/geral/noticia/201507/entidades-criticam-novo-modelo-de-cisternas-feito-de-plastico. 
Noronha, Gustavo. 16/3/2017. "A transposição do São Francisco não é só festa". CartaCapital (São Paulo). https://www.cartacapital.com.br/blogs/brasil-debate/atransposicao-do-sao-francisco-nao-e-so-festa.

Oliveira, Ariovaldo Umbelino de. 2011. “Não Reforma Agrária e Contra Reforma Agrária no Brasil do governo Lula". XIII Encuentro de Geógrafos de América Latina (EGAL, 25 al 29 de julio 2011): Estableciendo puentes en la geografía latinoamericana, v. 1: 1-19. San José/ Costa Rica:

EGAL. http://observatoriogeograficoamericalatina.org.mx/egal13/Geografiasocioeconomica/Geog rafiaagrari/04.pdf.

Oliveira, Francisco de. $1981^{3}\left(1977^{1}\right)$. Elegia para uma re(li)gião. SUDENE, Nordeste. Planejamento e conflitos de classes (Série Estudos sobre o Nordeste, v. 1). Rio de Janeiro: Paz e Terra.

Osório, Manuel Luís (Marquez do Herval, Rio Grande do Sul). 27/6/1877. Anais do Senado. Rio de Janeiro.

"Os serviços das obras contra as sêccas na Parahyba". 22/2/1920. A União. Diario official do Estado (Parahyba): 1. Arquivo Maurílio Almeida (João Pessoa).

Pessoa, Epitácio Lindolfo da Silva. 20/8/1891. Anais da Câmara dos Deputados. Rio de Janeiro. Arquivo Nacional.

Id. (Petrópolis). 22/4/1915. Carta a Major Horacio Lins (jefe político en Paraíba). Arquivo Dr. Flávio Maroja/ Instituto Histórico Geográfico Paraibano (IHGP, João Pessoa). Serie Correspondência com Epitácio Pessoa, 1912-1928. JP (João Pessoa Cavalcanti de Albuquerque): CEP-A6.G1.P1, documento 003-11.

Id. 29/11/1915 y 30/11/1915. “Obras contra as secas e serviços públicos” (discursos en el senado). En: id. Discursos parlamentares (Perfis parlamentares, 7): 375-386 у 386-387. Brasília: Câmara dos Deputados, 1978.

Id. (Petrópolis). 5/5/1917. Carta a Feitosa Ventura. Arquivo Dr. Flávio Maroja/ IHGP. Serie Correspondência com Epitácio Pessoa, 1912-1928. JP: CEP-A6.G1.P1.

Id. 3/5/1920. "Mensagem apresentada ao Congresso Nacional na abertura da terceira sessão da décima legislatura a 3/5/1920". En: id. Obras completas de Epitácio Pessoa, v. XVII, 15-207. Rio de Janeiro: Ministério da Educação e Cultura/ Instituto Nacional do Livro, 1956. 
Id. 3/5/1921. "Mensagem apresentada ao Congresso Nacional na abertura da primeira sessão da décima primeira legislatura a 3/5/1921". En: ib., 209-412.

Id. 3/5/1922. "Mensagem apresentada ao Congresso Nacional na abertura da segunda sessão da décima primeira legislatura a 3/5/1922". En: ib., 413-603.

Id. 1/6/1922. "Mensagem Presidencial [3/5/1922]. Obras do Nordéste". A União. Diario official do Estado (Parahyba): 1. Arquivo Maurílio Almeida (João Pessoa).

Id. (Rio de Janeiro). 18/2/1928. Respuesta a la carta de João Suassuna (gobernador de Paraíba, 1924-28) del 4/2/1928. Arquivo Dr. Flávio Maroja/ IHGP. Serie Correspondência com Epitácio Pessoa, 1912-1928. JP: CEP-A6.G1.P1, doc. 005-12: 4-5.

Id. (Den Haag). 31/8/1928. Carta a João Pessoa (gobernador de Paraíba, 1928-30). Arquivo Dr. Flávio Maroja/ IHGP. Serie Correspondência com Epitácio Pessoa, 1912-1928. JP: CEPA6.G1.P1, doc. 023-5: 1-2.

Id. (Den Haag). 11/9/1928. Carta a Adalberto Pessôa. Arquivo Dr. Flávio Maroja/ IHGP. Serie Correspondência com Epitácio Pessoa, 1912-1928. JP: CEP-A6.G1.P1, doc. 12-062.

Id. (Rio de Janeiro). 30/10/1928. Carta a João Pessoa. Arquivo Dr. Flávio Maroja/ IHGP. Serie Correspondência com Epitácio Pessoa, 1912-1928. JP: CEP-A6.G1.P1, doc. 076-5.

Id. (Rio de Janeiro). 9/11/1928. Telegrama a João Pessoa. Arquivo Dr. Flávio Maroja/ IHGP. Serie Correspondência com Epitácio Pessoa, 1912-1928. JP: CEP-A6.G1.P1, doc. 086-5.

Id. (Rio de Janeiro). 15/11/1928. Telegrama a João Pessoa. Arquivo Dr. Flávio Maroja/ IHGP. Serie Correspondência com Epitácio Pessoa, 1912-1928. JP: CEP-A6.G1.P1, doc. 096-5.

Id. 1957 (1925¹). Pela Verdade (Obras completas de Epitácio Pessoa, v. XXI, 1ª parte). Rio de Janeiro: Ministério da Educação e Cultura/ Instituto Nacional do Livro.

Pessoa, Helena Sayão. 1966. “Discurso em nome da família Epitácio Pessoa". Revista do Instituto Histórico e Geográfico Brasileiro (Rio de Janeiro: Departamento de Imprensa Nacional) 268 (julio-sept. 1965): 135-140.

Pessoa, João (Parahyba). 2/11/1928. Telegrama a Epitácio Pessoa. Arquivo Dr. Flávio Maroja/ IHGP. Serie Correspondência com Epitácio Pessoa, 1912-1928. JP: CEP-A6.G1.P1, doc. 039-1.

Id. 10/11/1928. Telegrama a Epitácio Pessoa. Arquivo Dr. Flávio Maroja/ IHGP. Serie Correspondência com Epitácio Pessoa, 1912-1928. JP: CEP-A6.G1.P1, doc. 041-1. 
Plataformaosc (Plataforma por um Novo Marco Regulatório para as Organizações da Sociedade Civil). 2016. ASA Brasil - Cisternas de plástico custam mais que o dobro das cisternas de placa. http://plataformaosc.org.br/asa-brasil-cisternas-de-plastico-custam-mais-que-odobro-das-cisternas-de-placa.

Portal Brasil. 6/5/2016. Dilma: "governo é feito de escolhas, nós escolhemos fazer a Integração do São Francisco". www.brasil.gov.br/governo/2016/05/dilma-governo-e-feito-de-escolhasnos-escolhemos-fazer-a-integracao-do-sao-francisco.

Id. 9/5/2016a. Moradores do sertão nordestino temem retrocesso com afastamento de Dilma. www.brasil.gov.br/governo/2016/05/moradores-do-sertao-nordestino-temem-retrocessocom-afastamento-de-dilma.

Id. 9/5/2016b. Programa Cisternas democratiza acesso à água no Semiárido. www.brasil.gov.br/cidadania-e-justica/2016/05/programa-cisternas-democratiza-acesso-aagua-no-semiarido.

Queiroz, Francisco Pessôa de (director del Jornal do Commercio). 15/10/1922. “O futuro govêrno. Em territorio mineiro, em amistosa palestra com o sr. dr. Pessôa de Queiroz, o presidente eleito da Republica faz importantes declarações - As grandes obras do Nordéste - Como o sr. Arthur Bernardes encara o palpitante problema". A União. Diario official do Estado (Parahyba): 1, publicado originalmente el 11/10/1922, en: Jornal do Commercio (Recife). Arquivo Maurílio Almeida (João Pessoa).

Ramos, Gilvan Alves (Campina Grande/ Paraíba; agrónomo, analista económico de la Empresa Brasileira de Pesquisa Agropecuária/ EMBRAPA). 8/4/2012 y 12/12/2016. Correspondencia con Tim Neufert.

Retumba, Francisco Soares da Silva. 1912. "Memória sobre os melhoramentos de que precisa a província da Paraíba, 1886". Revista do IHGP (Parahyba: Imprensa Official) IV (4): 163-228. Citado por Ferreira, 1993: 57.

Rodrigues Junior (Ceará). 11/2/1879. Anais da Câmara dos Deputados. Rio de Janeiro. Arquivo Nacional.

Santiago, Vandeck. 2010. “O Nordeste depois de Lula. 30 presidentes e duas verdades incômodas". Diário de Pernambuco (Especiais on-line). diariodepernambuco.com.br.

Schmitt, Tobias. 2013. Dürre als gesellschaftliches Naturverhältnis. Eine politische Ökologie der Wasserknappheit im Nordosten Brasiliens (Tesis doctoral, manuscrito inédito). Innsbruck: 
Leopold-Franzens-Universität/ Institut für Geographie, Fakultät für Geo- und Atmosphärenwissenschaften.

Silveira, Rosa Maria Godoy. 1984. O regionalismo nordestino: existência e consciência da desigualdade regional. São Paulo: Ed. Moderna.

Id. 1993. "Apresentação". En: Ferreira, 1993: 9-11.

Suassuna, João (Parahyba; gobernador, 1924-28). 4/2/1928. Carta a Epitácio Pessoa. Arquivo Dr. Flávio Maroja/ IHGP. Serie Correspondência com Epitácio Pessoa, 1912-1928. JP: CEP-A6.G1.P1, doc. 004: 1-4.

Superintendência do Desenvolvimento do Nordeste (SUDENE)/ Ministério do Interior. $1967^{2}\left(1959^{1}\right)$. Uma política de desenvolvimento econômico para o Nordeste (Estudo elaborado pelo Grupo de Trabalho para o Desenvolvimento do Nordeste). Recife: SUDENE.

Toledo, José Roberto et al. 28/10/2014. “Os sete mitos das eleições de 2014”. Estadão (São Paulo).

http://www.estadao.com.br/infograficos/os-sete-mitos-das-eleicoes2014,271980.htm.

Trigueiro, Oswaldo. 1982. A Paraíba na primeira república. João Pessoa: A União Editora.

Villa, Marco Antonio. 2001. Vida e morte no Sertão. História das secas no Nordeste nos séculos XIX e XX. São Paulo: Editora Ática.

Id. 2005. "Que braseiro, que fornalha". Nossa História (Rio de Janeiro: Biblioteca Nacional) 2 (18: abril): 14-19.

WBGU/ Wissenschaftlicher Beirat der Bundesregierung Globale Umweltveränderungen (ed.). 1998. Welt im Wandel: Wege zu einem nachhaltigen Umgang mit Süßwasser. Jahresgutachten 1997. Berlin/ Heidelberg/ New York/ Barcelona/ Budapest/ Hongkong/ London/ Mailand/ Paris/ Santa Clara/ Singapur/ Tokio: Springer. 